\title{
O MOVIMENTO HIGIENISTA COMO POLÍTICA PÚBLICA: ASPECTOS HISTÓRICOS E ATUAIS DA MEDICALIZAÇÃO ESCOLAR NO BRASIL
}

\author{
EL MOVIMIENTO HIGIENISTA COMO POLÍTICA PÚBLICA: ASPECTOS \\ HISTÓRICOS Y ACTUALES DE LA MEDICALIZACIÓN ESCOLAR EN BRASIL
}

\author{
THE HYGIENIST MOVEMENT AS A PUBLIC POLICY: HISTORICAL AND \\ CURRENT ASPECTS OF SCHOOL MEDICALIZATION IN BRAZIL
}

\author{
Fabiola COLOMBANI ${ }^{1}$ \\ Raul Aragão MARTINS ${ }^{2}$
}

RESUMO: Este artigo faz uma discussão acerca da medicalização escolar presente no mundo contemporâneo e sua relação com o movimento higienista implantado como política pública no início do século XX, como também, a participação dos laboratórios farmacêuticos no crescente aumento do uso de psicotrópicos na infância. A união composta entre a saúde e a educação produz um olhar biologizante que estigmatiza e individualiza àqueles que apresentam dificuldades no âmbito escolar. Respaldados por uma visão hegemônica, tal prática sustenta uma maquinaria proveniente de uma tecnologia política que domina e abre brechas para a governamentalidade. Assim, este trabalho destina-se a discutir o processo de patologização e medicalização da infância e suas implicações no campo das políticas públicas à luz da teoria Genealógica de Michel Foucault, que por meio da Biopolítica faz uma crítica alusiva à escola por essa tendência em desrespeitar as subjetividades com condutas policialescas "em defesa" de uma sociedade que desconsidera as relações interpessoais e se posiciona como um aparato regulamentador.

PALAVRAS-CHAVE: Medicalização. Políticas públicas. Biopolítica. Educação.

RESUMEN: Este artículo hace una discusión sobre la medicalización escolar presente en el mundo contemporáneo y su relación con el movimiento higienista implantado como política pública a principios del siglo $X X$, así como la implicación de laboratorios farmacéuticos en el creciente aumento en el uso de psicotrópicos en la niñez. La Unión compuesta por la salud y la educación produce una mirada biologizante que estigmatiza e individualiza a quienes presentan dificultades en la escuela. Respaldada por una visión hegemónica, esta práctica sustenta la maquinaria de una tecnología política que domina y abre lagunas para el gobierno. Así, este trabajo pretende debatir el proceso de

${ }^{1}$ Doutora em Educação e Pós- Doutoranda em Psicologia da Educação pela UNESP de Marília- e-mail: fabicolombani@hotmail.com

${ }^{2}$ Professor do Departamento de Educação do Instituto de Biociências, Letras e Ciências Exatas - São José do Rio Preto -IBILCE - UNESP e do PPG/ Educação UNESP - Marília - e-mail: raul@ibilce.unesp.br 
Patologização y medicalización de la niñez y sus implicaciones en el campo de las políticas públicas a la luz de la teoría genealógica de Michel Foucault, que a través de la biopolítica se hace una crítica a la escuela para esta tendencia a ignorar las subjetividades con conductos Policialescas "en defensa" de una sociedad que ignora las relaciones interpersonales y se posiciona como un aparato regulador.

PALABRAS CLAVE: Medicalización. Política pública. Biopolítica. Educación.

SUMMARY: This article discusses the medicalization on the school, which is present in the contemporary world and have a relationship with the hygienist movement implanted as public policy in the early twentieth century, as well as the participation of pharmaceutical laboratories in the growing increase in the use of psychotropic drugs in childhood. The union between health and education produces a biological vision that stigmatizes and individualises those who present difficulties in the school environment. Thus, this work aims to discuss the process of pathologization and medicalization of childhood and its implications in the field of public policies in the light of Genealogical Theory of Michel Foucault, who through Biopolitics makes a critique allusive to the school for this tendency to disrespect the subjectivities with police conducts "in defense" of a society that disregards interpersonal relations and positions itself as a regulatory apparatus.

KEYWORDS: Medicalization. Public policies. Biopolitics. Education

O corpo é uma realidade biopolítica; a medicina é uma estratégia biopolítica.

(Michel Foucault, 1979, p. 80)

Vivemos em uma sociedade envolta por problemas coletivos, sociais, políticos e econômicos que atingem as instituições, perpetuando as desigualdades surgidas ao longo do tempo. O sistema capitalista, a necessidade de consumo e produção, a homogeneização dos desejos e das condutas desqualificam aquele que se comporta de maneira diferente diante do que está posto ou instituído. Ao mesmo tempo, essa lógica se inverte e o diferente passa a ser individualizado, sendo apartado de suas condições históricas e sociais.

Nesse processo vicioso e contínuo surgem explicações com foco no corpo biológico, pautadas em um saber científico que endossa os ideais e promovem a prática, constituindo com isso o estatuto de ciência moderna. Porém, tais condutas estão em vigência há décadas, ou seja, não é algo próprio da contemporaneidade; a história é capaz de mostrar que estamos a naturalizar muitas das medidas praticadas nos diversos âmbitos sociais. Dito de outro modo, as pessoas que se diferenciavam por seu posicionamento 
questionador ou por não seguirem as normas impostas socialmente foram segregadas ou extinguidas pelo incômodo que causavam. Na perseguição usavam-se de armas concretas e o perseguido tinha como destino a finitude da vida, de forma rápida e precisa. A partir do século XX novas estratégias foram sendo construídas e cada vez mais se adotaram medidas simbólicas que pudessem conter os que poderiam causar uma "desordem social", ou seja, a atenção foi voltada aos que não se adaptavam às regras pré-estabelecidas, impostas por diversas esferas sociais.

Com o advento da ciência médica moderna, esta passou a incorporar a tarefa de atuar como aparato normatizador, criando critérios para identificar binômios como: saúdedoença, normal-anormal, ordem-desordem, louco-não louco e por fim, raças superioresinferiores. Ao passar pelo crivo pré-concebido do que é esperado, desejado e aceito, marginalizou-se desde então o diferente, vendo-o como algo a ser combatido e eliminado. Contudo, os bons costumes, a moral, as doenças físicas e psíquicas passaram a ser vistos sob uma ótica higienista, o que instituiu a rejeição dos indivíduos que destoariam dos padrões ditos normais, excluindo-os ou silenciando-os de várias formas.

Inicialmente, antes de focar o problema que move este artigo - a medicalização escolar - é importante destacar que tal questão é parte de um processo mais amplo, a biologização da vida, que tem como efeito a medicalização em seus vários seguimentos, tanto da sociedade, quanto da educação e do escolar. Assim, consideramos de suma importância elucidar como se dá o conceito de medicalização e sua origem, que embora muito difundido na atualidade, ainda é passível de más interpretações. Há quem pense que medicalizar é o ato de administrar medicamentos a outrem, quando na verdade tal conceito é muito mais amplo e significativo.

Ivan Illich (1975), no livro Nêmesis da Medicina, descreve a produção da cultura medicalizada em uma dimensão social e política. Para ele, que conservava um discurso ácido sobre o poder médico, medicalizar significa determinar em termos médicos problemas sociais, desviando-se de sua verdadeira origem, ou seja, ao invés de se pensar nos conflitos que emergem das relações humanas e do modo de funcionamento do sistema como um todo, cria-se patologias que ficam limitadas a serem pensadas como manifestações individuais, responsabilizando com isso o corpo biológico, esquecendo-se que o corpo também é político e habita em uma sociedade, o que faz com que ele carregue consigo todas as formas de ser e viver construídas naquele habitat. Além disso, esse poder médico sempre incomodou Illich, pela própria superioridade de parecer vencer a morte e 
ter nos diagnósticos uma fidedignidade soberana que parece estar acima de qualquer suspeita ou engano.

Moysés e Collares, (1997, p.14), contribuem dizendo que: “[...] o processo de medicalização individualiza problemas coletivos, biologizando-os e naturalizando-os". Desta forma, ao transformar questões sociais em questões médicas, perde-se a dimensão da ação e o foco passa ser o problema e o organismo vivo que o habita, procurando no substrato biológico explicações para as manifestações individuais.

Como bem descreve Guarido (2011, p. 30):

O conceito medicalização foi utilizado em diversos estudos, especialmente a partir da década de 70 do século XX, para tratar de uma maneira a partir da qual as vicissitudes do processo de aprendizado das crianças foram frequentemente traduzidas. O conceito medicalização foi também tomado para refletir sobre acontecimentos no interior das instituições escolares ocorridos quando da higienização das práticas escolares.

Ou seja, a higienização, como uma ação que se constitui como política pública no início do século XX, uniu saúde e educação com a finalidade de alcançar os escolares e suas famílias, o público e o privado. Guiados pelas ideias eugenistas de Galton, Morel e Lombroso, a medicina passou a ver o professor como aliado, treinando-o, desenvolvendo nele o "olho clínico" e, assim, tornando-o coadjuvante dos diagnósticos, partindo de um modelo positivista de normalidade que vinha escudado por um discurso científico. O professor passara então a pensar além das questões metodológicas de sala de aula, devendo identificar os alunos anormais e tomar providências para "endireitá-los" expressão utilizada pelo médico Carlos Sá, inspetor sanitário do Departamento Nacional de Saúde Pública, que ficou famoso por criar os "Pelotões de Saúde" (MARQUES, 1994).

Nos "Pelotões de Saúde" havia uma investigação acerca do cotidiano da criança, que regulavam desde a escovação dos dentes até a formação do caráter. A partir daí surgiram nas escolas condutas que se caracterizavam como higiene mental e diversos dispositivos normalizadores, que se instituíram por meio da inspeção médica, ficha sanitária do aluno (preenchida pelo professor todos os dias) e da figura do professor soldado, cujo currículo de formação passou a ter disciplinas de conteúdo das áreas médica e biológica.

Assim, fica claro que a instituição escolar foi marcada pelo poder disciplinar, que nasceu no cenário de uma sociedade eugenista e higienista e fez do corpo biológico 
instrumento de análise e de investidas políticas, com o propósito de extinguir todo comportamento indesejável. Com isso, a educação passa a banhar-se nas águas da medicina social e a construir uma cumplicidade ideológica que marcou desde então, a prática educacional no Brasil.

Assim, a história da educação começa a ser delineada e influenciada por ações provenientes de ideais europeus, em que a educação pedia por cuidados médicoassistencialistas, com interesse em analisar e orientar o comportamento humano, em construir dispositivos dentro dos padrões positivistas para obter um poder sobre a vida - o Biopoder.

Este investimento político do corpo está ligado, segundo relações complexas e recíprocas, à sua utilização econômica; é, numa boa proporção, como força de produção que o corpo é investido por relações de poder e de dominação; mas em compensação sua constituição como força de trabalho só é possível se ele está preso num sistema de sujeição (onde a necessidade é também um instrumento político cuidadosamente organizado, calculado e utilizado); o corpo só se torna força útil se é ao mesmo tempo corpo produtivo e corpo submisso. (FOUCAULT, 2008a, p. 25)

Foucault chama tal estratégia de "guerra de raças", uma vez que a influência europeia nas ações políticas brasileiras que levam às práticas eugênicas deixa claro que há raças superiores e inferiores e que os comportamentos aparentes desta última devem ser abolidos para o bem social. Tal ideal foi se consolidando em torno de ações disciplinares, que foca no corpo individual e o considera como uma máquina, sendo analisado sob uma ótica anátomo-patológica; porém, mais tarde, desdobra-se para uma ação coletiva e a ação política do corpo humano passa a se estender à população, com interesse de controlar os processos biológicos, tais como: nascimento, mortalidade, natalidade, qualidade de vida e saúde - o que Foucault (1979), vem chamar de biopolítica da população.

O pensamento higienista seria, então, uma das formas disciplinares que surgiram com o objetivo de reestruturar o núcleo familiar, mas isso só ocorre através do poder médico que se insere na política de transformação do coletivo, para compensar as deficiências da lei e entrar no espaço da norma. No casamento higienista deveriam existir três princípios básicos: o status social, uma boa saúde física e uma boa formação moral. Estes "pré-requisitos" para uma boa união atenderiam o objetivo principal da ordem higienista-médica, para possibilitar condições de produzir uma norma familiar capaz de 
formar cidadãos domesticados, normatizados, higienizados e individualizados, que se tornariam aptos a colaborar com o progresso da cidade, do Estado, enfim, da Pátria.

\section{Biopolítica e normalização: condutas de interferência nos valores e nos hábitos da população.}

No que se refere à noção de normalização, Foucault apresenta com precisão em Segurança, território, população (2008b, p. 58), a forma com que a disciplina e a norma se fizeram presente na base sustentável de uma nova política voltada para a "poda" de qualquer conduta que incitasse o desvio. A normalização disciplinar consiste em traçar primeiro um modelo, um modelo ótimo que está construído em função de um determinado resultado, e a operação de normalização disciplinar consiste em tratar de conformar as pessoas, os gestos, os atos a este modelo. A norma tem um caráter primariamente prescritivo, e a determinação e distinção entre o normal e o anormal resulta em possibilidades decorrentes dessa norma postulada. Assim, a escola foi pensada para ser esse lugar de aplicação da norma, das prescrições pré-estabelecidas, que serviria como dispositivo para o alcance da ordem social. A ética e os valores ordenavam às condutas no convívio social, modelando o indivíduo para que sua vida privada e familiar seguisse atrelada aos anseios políticos de uma determinada classe social - a burguesia.

É mais fácil visualizar este processo quando se analisam os resultados alcançados pela educação higiênica, que levou a medicina para dentro dos bairros, das escolas e das famílias para construir uma obrigatoriedade na forma de cuidar do corpo e da vida, um sistema público para se pensar o desejo coletivo do progresso. Embora a educação higiênica tenha sido focada em um corpo individualizado, influenciou e manipulou tanto política como economicamente a vida social. Mas estes resultados foram obtidos por meio do controle moral, mediante o qual se ensinava que a boa educação estaria nas condutas civilizadas e no autocontrole dos impulsos e desejos.

Para Boarini (2003), a educação higiênica no início do século XX, veio disposta a refinar e a racionalizar a primitiva sociedade colonial, gerando um processo de hierarquização social da inteligência e das boas maneiras. Instalou-se a ideia de que ser culto era superior ao ser inculto, de que uma vida abastada de conhecimento proporcionaria uma vida feliz, uma nova forma de viver, uma maneira consciente de 
pensar e de sentir, enfim, um pouco daquilo que os gregos chamavam de éthos - na medida que adota uma forma prática da superação do próprio limite.

Estabeleceu-se assim, a razão como principio fundamental para orientar a vida das pessoas, a fim de que se pudesse alcançar a civilização das cidades. Os higienistas acreditavam que se o controle do corpo fosse feito desde a infância, as condutas na fase adulta já estariam condizentes com o ideal desejado, isto é, uma criança bem fiscalizada seria o perfeito adulto higiênico. Porém, essas condutas não propiciavam o desenvolvimento da conscientização no sentido de levar os indivíduos a mudarem suas visões de mundo. A ação das normas educativo-terapêuticas se instituiu de forma despolitizada, individualizante, reduzindo o indivíduo a um mero produto de seu intimismo psicológico, sem levar em consideração às próprias necessidades sócio emocionais.

Com a necessidade do avanço social, a alfabetização e a entrada do homem no mundo da razão passou a ser algo necessário, a escola o local primordial para a infância, sendo o lugar por excelência mais apropriado para a medicina influenciar o comportamento de cada aluno, imprimindo ali o seu poder, visto que a família estaria distante daquelas ações e ainda seria diretamente beneficiada" com a modificação das condutas de seus filhos. Desta forma, os higienistas passaram a pensar que, ao invés de castigar os cidadãos, deveriam prevenir pensando no adulto do amanhã, construindo seres sujeitáveis, submissos, obedientes, enfim, disciplinados.

A disciplina para Foucault tem ligação direta com o poder, pois segundo ele o poder é a ação das forças em detrimento de algo ou de alguém que exerce fragilidade ou submissão em relação ao outro. O olhar hierárquico, que estigmatiza e reprime o que não é aceitável, tem como objetivo disciplinar o corpo dócil - termo usado por Foucault - que está adjacente a uma época clássica em que o corpo foi tido como um alvo de poder. Os higienistas se utilizaram, em suas investidas, de um corpo que pode ser manipulado, modelado, treinado, que obedece e corresponde aos desejos dos detentores do poder que, neste caso, está caracterizado na figura médica.

[...] O corpo humano entra numa maquinaria de poder que o esquadrinha, o desarticula e o recompõe. Uma "anatomia política", que é também igualmente uma "mecânica do poder",está nascendo; ela define como se pode ter domínio sobre o corpo dos outros,não simplesmente para que façam o que se quer,mas para que operem como se quer,com as técnicas,segundo a rapidez e a eficácia que se determina.A disciplina fabrica assim corpos submissos e exercitados,corpos “dóceis".A disciplina aumenta as forças do corpo(em termos econômicos de 
utilidade) e diminui essas mesmas forças (em termos políticos de obediência).(FOUCAULT,2008a,p.119).

Uma vez que ações de natureza hegemônica vão ganhando espaço na educação, medicalizar o diferente se tornou prática, com leis e argumentos próprios, pautados em uma sociedade de controle que despotencializa a criança com o intuito de mantê-la em estado de submissão e heteronomia, para torná-lo mais fácil de ser governado e dominado - o controle do corpo dócil que pode impedir brutalmente o alcance à autonomia.

Desta forma, com foco na escola - nosso campo de interesse - a ideia de que a criança deve ser tratada individualmente por que ela é detentora de um transtorno ou distúrbio, distorce abruptamente a origem do problema, o que "demoniza" o aluno que não se enquadra aos padrões desejados, tornando a escola vítima de alunos inadequados. Como comenta Garrido e Moysés (2011, p. 150):

É nessa conjuntura que ganha status de verdade a ideia de que alunos que não aprendem na escola têm, em si, um problema. Nas últimas duas décadas vêm sendo cada vez mais aceita, no Brasil, a ideia de que as dificuldades escolares de uma criança são causadas por problemas de ordem médica. Essa certeza abre espaço para profissionais da saúde, exames, rótulos, diagnósticos, remédios, todos voltados a legitimá-la e a transformar crianças em crianças-problema ou anormais.

A partir do que foi exposto anteriormente podemos relacionar o surgimento da medicalização escolar às políticas públicas ligadas à saúde e à educação, que se constituíram no início do século XX, porém, em um segundo momento há outro elemento imprescindível que merece ser analisado - as ações das indústrias farmacêuticas. Munidas de um forte poder econômico e de ações apelativas que vendem a ideia de promoção de saúde, tais indústrias produzem saber e convencem por meio de informações distorcidas e parcerias com profissionais descomprometidos, implantando no ideário coletivo necessidades medicamentosas sem nenhuma cautela.

Assim, nossa discussão segue permeada pela necessidade que temos de refletir sobre outras ações externas que chegam como panaceia e que influenciam diretamente em ações políticas, justificadas muitas vezes por fenômenos com pouca ou nenhuma base fidedigna.

\section{A indústria farmacológica entre o saber e o poder: as "drogas da obediência"}


A indústria farmacológica, grande potência mundial que perde somente para a de materiais bélicos, teve início no século XIX, “[...] quando vários compostos químicos, incluindo alcaloides como morfina, estriquinina, quinina, nicotina e cocaína, foram isolados e produzidos em massa" (CALIMAN e DOMITROVIC, 2013, p. 880), e desde a segunda metade do século XX, até os dias atuais tem crescido de forma expressiva, chamando a atenção inclusive da OMS (Organização Mundial de Saúde). A indústria farmacêutica se utiliza de uma sequela histórica que constitui as dificuldades escolares como doença e não respeita a subjetividade humana, buscando a padronização e o alinhamento homogêneo das diversas formas de ser e viver, o que é impossível quando falamos de seres humanos. Isso se deve à forma com que a sociedade atual vem buscando estruturar seu funcionamento. Ocorre uma necessidade de padronização em tudo, isso é visível e aceito socialmente sendo visto como tendência que vai desde o enquadramento à moda, à estética e até mesmo à construção civil e a todos os produtos disponíveis no mercado.

A sociedade tende a caminhar como um "enxame de abelhas", pendendo para um lado ou para outro; isso, a nosso ver, não é uma forma de expressar a coletividade, mas sim de massificação e homogeneização humana. Mas e quando o assunto é eleger e apontar o diferente tentando em um segundo momento modificá-lo? Em nossa opinião, isso é mais grave e preocupante, pois põe em risco a singularidade e a criatividade do aluno, como também, a saúde. Diante disso, uma vez percebido como diferente, passa a internalizar tais repulsas sociais, convencendo-se de que possui algo a ser curado.

Nesse processo de diagnose, ocorre a patologização que precede à medicalização e traz como consequência a necessidade de recorrer a psicofármacos no tratamento das dificuldades escolares. Se a patologização é a ponta inicial e o uso de psicofármacos é o efeito da causa, temos aqui dois momentos decisivos: o início quando se patologiza e o final do processo quando se opta por fazer uso de psicotrópicos com o fim de implantar como "metodologia de mudança" as drogas, conhecidas como "drogas da obediência".

Como caráter de informação, vamos esmiuçar dois termos importantes para pensarmos a questão. Patologização - ato de patologizar - vem de patologia, cuja origem é a palavra grega pathos, que significa, principalmente, passividade, sofrimento e assujeitamento, o que torna o sujeito passível de controle e poder, enfim, termos usados por Foucault (2008a) - um corpo dócil. Psicofármacos - Psico+Fármacos - Psico palavra de origem grega Psiquê - que significa mente e alma e fármaco da palavra grega 
Phármakon- que tem dois sentidos: remédio e veneno, ou seja, vemos aqui que uma vez assujeitado e submisso o aluno pode passar pelo processo de "envenenamento da alma". Temos sempre um medicamento em mãos, temos o hábito de recorrer a drogas como soluções mágicas, sem nos preocuparmos em ouvirmos o corpo, as reações e seus sintomas. Somos influenciados por uma mídia que banaliza as drogas lícitas e condenam as ilícitas como se ambas não fossem prejudiciais ao corpo e à alma. Recorremos às drogas para que elas façam o que as relações humanas não conseguem fazer.

Neste contexto, anfetaminas como o Metilfenidato que se apresenta com dois nomes comerciais Ritalina ${ }^{\circledR}$ e Concerta ${ }^{\circledR}$, têm sido prescritas como medicamentos "auxiliadores" para potencializar a atenção e o desempenho escolar. Como dizem Eidt e Tuleski (2007, p.230):

[...] as medicações muitas vezes são utilizadas como mais um instrumento de modelação subjetiva, de formatação de padrões de normalidade; são as tentativas de utilização das medicações para constituir um sujeito sem conflitos, sem angústias, sem limitações.

Quando o Metilfenidato foi descoberto, "não havia um diagnóstico específico para seu uso. Era indicado para tratar a fadiga presente em vários quadros psiquiátricos, como também para minimizar o cansaço em idosos" (ORTEGA, 2010, p.245). Brant e Carvalho (2012, p. 627) comentam ainda mais sobre a história da Ritalina:

Havia um ostensivo empenho para se descobrir uma aplicação terapêutica para esse fármaco que pudesse justificar sua aplicação medicinal em função da alteração fisiológica produzida. A indicação para transtornos hipercinéticos - dificuldades em manter a atenção, com ou sem hiperatividade - pareceu constituir uma justificativa "cientificamente convincente" para sua aplicação.

É assim que a indústria farmacêutica funciona, cada fabricante tem o direito de lançar o medicamento, desde que seja para uma doença específica. Não há como colocar o medicamento no mercado sem que a doença exista ou que sirva para várias patologias. Desta forma, é de interesse do fabricante que a categoria da doença seja alargada, por este motivo a indústria farmacológica investe tanto em pesquisas e divulgações do medicamento, com a finalidade de que a substância química lançada possa abranger o máximo de sintomas. Especificamente falando, "é a partir da produção de metilfenidato que se cria uma patologia, o TDA/H. Ou seja, primeiro inventou-se o remédio, para, depois, se forjar a doença" (BRANT e CARVALHO, 2012, p. 632). 
Angell (2007) traz em sua obra uma denúncia contra os laboratórios farmacêuticos, nos elucidando sobre como essa indústria tão lucrativa conquista há vários anos o ranking das indústrias que mais faturam nos Estados Unidos, o que acaba por influenciar vários países. Segundo aponta Luengo (2010, p. 62):

No Fortune 500 as dez indústrias que mais faturam são as indústrias farmacológicas. O seu total bruto de rendimento supera as 490 empresas restantes. Em primeiro lugar estão os medicamentos de doenças cardiovasculares, em segundo, estão os medicamentos que atuam no SNC.

Acreditamos ser alarmante a forma com que o metilfenidato vem sendo comercializado, ou seja, livremente e utilizado sem critérios ou precauções. Seu uso é muito comum nos diagnósticos de TDA ou até mesmo de TDAH, porém como ressalta Brant e Carvalho (2012, p. 628) “[...] sua utilização já ocorre entre empresários e estudantes, para fins de emagrecimento e uso recreacional", como também, para melhoria de funções cognitivas em pessoas saudáveis. Embora o metilfenidato já tenha passado por modificações em sua estrutura molecular desde a sua existência, para amenizar os efeitos indesejáveis, ele continua uma droga altamente propensa à dependência química, como sua própria bula e capaz de mostrar e mesmo assim, é muito acessível em sua comercialização, o que facilita a compra.

Apesar dos alertas presentes nas bulas e a distribuição ser realizada apenas com o receituário tipo A (cor amarela), o cenário que temos hoje é de um consumo exacerbado: "o metilfenidato é o psicoestimulante sintético mais consumido no mundo, superando todos os outros somados" (ITABORAHY, 2009, p.8). Porém, segundo Carlini, Nappo, Nogueira e Naylor (2003, p. 11):

Neurologistas e psiquiatras argumentam que o controle de metilfenidato deve existir, mas em se tratando de um medicamento prescrito por especialistas e de não possuir grande potencial de dependência, o receituário azul já seria suficiente.

O metilfenidato, usado principalmente no tratamento de TDA/H, tem como base a anfetamina, é vendida somente com receita A e neurologistas e psiquiatras afirmam que tal droga não possui grande potencial de dependência. E ainda querem mudar a classificação do medicamento mudando para receita azul para facilitar ainda mais a comercialização. Qual é o interesse que está por trás disso? Quais benefícios são oferecidos pelos laboratórios para tal feito? A refletir. 
De acordo com o site do Instituto Brasileiro de Defesa dos Usuários de Medicamentos (IDUM, 2013), nos últimos anos houve um aumento expressivo no consumo de Ritalina ${ }^{\circledR}$ ou metilfenidato, substância esta que ficou conhecida como "droga da obediência”. Em 2000, foram vendidas 71 mil caixas desses medicamentos e em 2010 as vendas atingiram a assombrosa marca de 2.000.000 de caixas. Os dados do (IDUM, 2013), mostram também, um consumo crescente, como é o caso do município de São Paulo (SP), que passou de 110.300 comprimidos em 2009 para 180.000 em 2010 e, dados até o mês de maio de 2011, registram o consumo de 150.000 comprimidos (Fonte: Conselhos Municipais de Saúde de São Paulo, 2013).

Os números apresentados serviram de base para que a situação se agravasse, pois a partir de tais dados surgiu a presença de projetos de lei, no âmbito federal, estadual e municipal, que indicam a tentativa de inserir o tratamento e o diagnóstico de dislexia e TDAH como política pública nos níveis federal, estadual e municipal. Tal questão teve vários desdobramentos, exigindo inclusive um posicionamento frente à medicalização dos conselhos profissionais de Psicologia, Fonoaudiologia e Assistência Social, como também, dos sindicatos e centrais sindicais, universidades, parlamentares parceiros do fórum sobre medicalização e dos movimentos sociais ligados às entidades e associações.

Houve em especial, um projeto de lei de $n^{\circ} 7031 / 2010$ que dispõe no Congresso Nacional sobre o tratamento de Dislexia e do TDAH na educação básica. Tais projetos representam o empenho para que medidas de implantação de reconhecimento e diagnóstico da Dislexia e TDAH ocorram. Isso se deve aos números alarmantes de crianças encaminhadas e supostamente de crianças que passaram a usar o metilfenidato e outras drogas para o tratamento de tais transtornos.

Vejamos então o percurso: patologizam-se as manifestações escolares, o professor produz a queixa escolar, ocorre a medicalização, encaminham-se os alunos, os especialistas prescrevem os medicamentos, os profissionais da saúde acompanham e nossos governantes? Preocupam-se apenas com a "ponta do iceberg"? Mandam projetos de lei às diferentes estâncias para que os transtornos sejam reconhecidos e os professores treinados para o diagnóstico ainda em sala de aula?

Tudo parece fazer parte de um círculo vicioso e ocorre com base nos números expostos, tanto de aumento das vendas dos medicamentos, quanto dos números de encaminhamentos realizados. E ninguém questiona a ocorrência de tal fenômeno? Nós que estamos aqui refletindo sobre tal problema, escapamos de sermos encaminhados, não 
fizemos parte da "geração Ritalina", nossas dificuldades escolares eram sanadas com esforço e reforço escolar, nossas peraltices tinham duas explicações: precisávamos ser mais educados ou nossas atitudes eram coisas de criança. Porém, atualmente o que mais nos causa impacto é que estamos vivendo em uma sociedade muito diferente daquela que vivíamos há décadas, estamos vivendo, como diz a psicóloga Roseli Sayão em uma matéria publicada no jornal Folha de São Paulo do dia 11/02/2014, uma "Profusão de Estímulos". Os adultos estão habituando-se a tantas novidades da tecnologia e as crianças, que já nasceram neste mundo de "profusão de estímulos", têm outra relação com a forma de manter a atenção, muito diferente daquelas que nós tínhamos quando crianças; sem aparelhos eletrônicos em excesso, sem jogos desafiantes e sem diversos estímulos sensoriais que ocorrem a todo o momento, por meio de diversos objetos, sons e imagens. E acreditamos que isso deve ser levado em consideração. A sociedade está doente ou estamos atravessando um processo de mudança em que tudo parece entrar em uma lógica mais acelerada e competitiva?

Nos últimos anos, o que vemos são as manifestações dos alunos serem rotuladas, etiquetadas com CID’s (Código Internacional de Doenças) e categorizadas pelo DSM (Diagnostic and Statistical Manual of Mental Disorders). Mas afinal, como são classificados, conceituados e descritos tais transtornos?

\section{As escolas frente à medicalização}

$\mathrm{Na}$ escola, esse processo de biologização e medicalização do diferente foca as causas do fracasso escolar na criança, o que desvia segundo Collares e Moysés (1985, p. 197), “[...] de uma discussão político-pedagógica para causas e soluções pretensamente médicas, portanto inacessíveis à Educação".

Ao haver esse deslocamento o caminho é sempre o mesmo, o aluno é patologizado e sua dificuldade vira alvo, o que acarreta na medicalização; e o problema apresentado desde o início ainda não é sanado, mas torna-se um problema individual e orgânico. Finalmente, ocorre o que vemos hoje de forma tão frequente, um crescente número de encaminhamentos de crianças e adolescentes aos profissionais da saúde, todos em busca “do fantástico mundo do Mágico de Oz”, ou seja, soluções rápidas e instantâneas buscadas fora da escola, com a ajuda de profissionais que não participam do ambiente escolar e que nada conhecem sobre a realidade educacional em questão. 
Tais profissionais - supostos saberes - credibilizam cientificamente as queixas escolares dos professores transformando-as em diagnóstico, mesmo que no conteúdo desses relatórios contenham somente causas imediatas, superficiais, individualizadas e concretas, explicando superficialmente o motivo pelo qual o problema surgiu. O relatório se torna então um instrumento de avaliação, a queixa escolar passa a ser materializada e muitas vezes carrega um teor de sentença, o que contribui para um ambiente escolar hostilizador que depõe contra o aluno, que o estigmatiza e o rotula, quando na verdade deveria ser um ambiente onde a essência se manifesta e por meio de parcerias altruístas surja à cooperação e o respeito.

Cada vez mais é possível perceber a relação construída entre saúde e educação. Essa interferência da medicina na saúde deixa nebuloso o verdadeiro motivo que leva a criança a um baixo aproveitamento escolar. O Fracasso Escolar deveria ser visto, segundo Collares e Moysés (1985, p. 8) como “[...] resultado de complexo jogo de fatores educacionais, sociais, culturais e econômicos, que refletem a política governamental para o setor social". Ao desconsiderar estes fatores, a criança passa pelo crivo preconceituoso da normalidade no qual, vítima de um aparelho social distorcido, passa a ser apontada como deficiente intelectual ou portadora de algum transtorno. Isso ocorre sob as lentes de uma pedagogia submissa à ciência médica e de uma medicina guiada pela psiquiatria biológica, a qual individualiza a criança e retira a responsabilidade do sistema educacional.

O Fracasso Escolar é um termo institucionalizado, presente na escola como problema, cuja existência - que já parece ser inquestionável -, opera produzindo saber. Porém, se antes o aluno fracassado era aquele que apresentava "desinteresse", “indisciplina" e "falta de educação", na atualidade é o aluno que apresenta algum tipo de disfunção cerebral de origem genética, capaz de causar deficiências e desordens no comportamento. A ciência médica atravessou o âmbito escolar e hoje a escola é um dispositivo institucionalizado, que foi produzido e produziu relações de saber-poder.

O cotidiano escolar é permeado por preconceitos, julgamentos prévios sobre os alunos e suas famílias e opiniões formadas a respeito da história de vida daqueles que demonstram alguma necessidade especial. Com isso, as justificativas acabam permanecendo na superficialidade e o não aprender fica restrito às condições econômicas, raça, credo, região onde mora ou no modo com que as famílias se organizam, como se o sistema educacional fosse perfeito e os alunos encontram-se completamente inadequados para essa escola que foi pensada para todos. 
Ora, isso não é algo decorrente do século XXI, mas novamente destacaremos aqui, é algo histórico! E está naturalizado por ser uma concepção cristalizada e aparentemente difícil de mudar. Nos momentos de grande tensão política e social, a resposta da sociedade se repete, e recorrer a uma ciência de matriz positivista, que enxerga o humano de forma calculativa é atender o interesse de uma determinada classe social. Assim sendo, o efeito de tal causa é a culpabilização da vítima, que dessa forma passa para o lugar de réu. Patto (2000), por exemplo, analisa como a visão psicométrica sustentou a culpabilização das crianças e de suas famílias e como serviram para colaborar com o favorecimento das classes dominantes e da ideologia burguesa. Envolta por pensamentos e condutas hegemônicas, a escola na modernidade vem fortalecendo as práticas disciplinares. Posto isto, remetendo-nos a Foucault (1979), essas práticas tornaram eficaz o modo de categorizar os indivíduos, classificando-os, localizando-os e registrando-os nos parâmetros da Norma.

A forma de ver os problemas de ensino-aprendizagem é banalizada, restringindo as doenças psíquicas à subjetividade, como também os diagnósticos e seus tratamentos; como se já não houvesse distinção entre repensar as diversidades e as dificuldades que surgem em nosso cotidiano e as drogas que parecem vir para que não mais tenhamos diversidades e dificuldades a serem enfrentadas na vida. Essa seria a ilusão plantada pelas indústrias farmacológicas? Fazem-nos acreditar que não precisamos sofrer, pois as pílulas estão ao nosso alcance e existem justamente para solucionar os problemas que surgem diariamente em nossas vidas.

\section{Considerações Finais}

Para finalizar, podemos concluir a partir do ponto inicial deste trabalho, que as ações do movimento higienista implantadas como políticas públicas para impor verdades e violar a liberdade, influenciaram diretamente às ações medicalizantes que estão sendo vivenciadas no cenário atual, no qual ainda se justifica o não aprender e os problemas existentes no cotidiano escolar como um fracasso do aluno, apartando-o de sua realidade social, individualizando-o e focando os conflitos no corpo biológico, desconsiderando completamente o coletivo e as relações interpessoais presentes na realidade escolar. 
A lógica medicalizante desvia e desconfigura o que deveria ser o mais importante: a preocupação com a melhoria do ensino, a atenção especial que devemos ter com as relações no âmbito escolar e a garantia de preservação da integridade e dos direitos da criança e do adolescente que é uma educação de qualidade, saúde, liberdade, respeito, dignidade e preservação da vida. Com a medicalização os direitos se invertem, a história passa a ficar "contaminada" por uma necessidade de normatização doentia, que estimula e viabiliza o diagnóstico, tornando o aluno um incapaz. Sim, um incapaz, pois uma vez que essa criança e esse jovem passa pelo rótulo de um diagnóstico dessa natureza, é posto que não há capacidade em aprender, que a única chance é se ele optar pelo tratamento químico que pode levá-lo à drogadição.

É necessário dar à criança a chance de aprender, e os educadores necessitam cuidar para que todos sejam respeitados em suas individualidades, inclusive no modo como aprendem, com um olhar cuidadoso e atento para aquilo que se interessam, sempre com o intuito de estimulá-las. "Que a escola e as professoras sejam capazes de avaliar as possibilidades de cada criança, acolher e ajudá-las a superar os seus próprios limites. Isto é o direito que cada um de nós deve ter; este é o direito que temos que defender" (MOYSÉS, 2010, p. 23).

A escola deve então ser por excelência, o lugar da criatividade, das manifestações genuínas. Não obstante, a medicalização impede o vir a ser, interrompe a dialética da vida que necessita de liberdade para ganhar força. Não se desenvolve bem, não aprende; não respira quem vive em repressão e controle. A infância é o momento crucial para a construção de uma personalidade curiosa, investigativa que no futuro, alicerçará um jovem ou adulto autônomo, capaz de gerir sua própria vida. Desta forma, as drogas não se fazem necessário, pelo contrário: sejam elas ilícitas ou lícitas elas podem impedir permanentemente o desenvolvimento moral da criança; o que representaria um contrassenso na e para a educação.

Agradecimentos: Nosso agradecimento ao Programa de Pós-Graduação em Educação da UNESP/Marília e ao órgão PNPD/CAPES, Programa Nacional de Pós-Doutorado da CAPES, por financiar a pesquisa de pós- doutorado que dá sustentação a este artigo. 


\section{Referências}

ANGELL, M. A verdade sobre os laboratórios Farmacêuticos. Tradução: Waldéa Rabinovitch. Rio de Janeiro: Record, 2007.

ARRUDA, Marco Antônio. Levados da Breca. Ribeirão Preto, 2006.

BOARINI,M.L. (org.) Higiene e Raça como projetos: higienismo e eugenismo no Brasil. Maringá PR: Eduem,2003.

BRANT, L.C.; CARVALHO, T.R.F. Methyl phenidate: medication as a "gadget" of contemporary life. Interface - Comunicação, Saúde e Educação, v.16, n.42, p.623-36, 2012.

CALIMAN, L.V.; DOMITROVIC, N. Uma análise da dispensa pública do metilfenidato no Brasil: o caso do Espírito Santo. Physis Revista de Saúde Coletiva, Rio de Janeiro, 23 [3]:879-902, 2013.

CARLINI, E.A; NAPPO, S.A; NOGUEIRA, V.; NAYLON, F.G.M. Metilfenidato: influência da notificação de receita A (cor amarela) sobre a prática de prescrição por médicos brasileiros. Revista de Psiquiatria clínica. São Paulo, vol.30,nº1,2003.

COLlARES, C. A. L.; MOYSÉS M. A. A. Fracasso Escolar uma questão médica? Caderno Cedes n ${ }^{\circ}$. São Paulo: Cortez,1985.

EIDT, N. M.; TULESKI, S. C. Discutindo a medicalização brutal em uma sociedade hiperativa. In: MEIRA, M. E.M; FACCI, M. G. D. (orgs.). Psicologia Histórico-Cultural: contribuições para o encontro entre a subjetividade e a educação. São Paulo: Casa do Psicólogo, 2007.

FOUCAULT, M. Microfísica do poder. Tradução de Roberto Machado. Rio de Janeiro: Edições Graal, 1979.

FOUCAULT, M. Vigiar e punir, 35ª ed. Petrópolis:Vozes,2008a.

FOUCAULT, M. Segurança, território, população. Curso no Collège de France (19771978). São Paulo: Martins Fontes, 2008b.

GARRIDO, J.; MOYSÉS, M. A. A. Um panorama nacional dos estudos sobre a medicalização da aprendizagem de crianças em idade escolar. In: Medicalização de crianças e adolescentes: conflitos silenciados pela redução de questões sociais a doença de indivíduos/ organizadores Conselho Regional de Psicologia de São Paulo; Grupo Interinstitucional Queixa Escolar. São Paulo: Casa do Psicólogo, 2011.

GUARIDO, R. A biologização da vida e algumas implicações do discurso médico sobre a educação. In: Medicalização de crianças e adolescentes: conflitos silenciados pela redução de questões sociais a doença de indivíduos/ organizadores Conselho Regional de psicologia de São Paulo; Grupo Interinstitucional Queixa Escolar. São Paulo: Casa do Psicólogo, 2011. 
IDUM. Instituto Brasileiro de Defesa dos Usuários de Medicamentos. Disponível em: <http://www.idum.org.br/>. Acesso em:10 de Junho de 2009.

ILLICH, I. A expropriação da saúde nêmesis da medicina. Rio de Janeiro: Nova fronteira, 1975.

ITABORAHY, C. A ritalina no Brasil: uma década de produção, divulgação e consumo. Dissertação (Mestrado) - Instituto de Medicina Social, Universidade do Estado do Rio de Janeiro, Rio de janeiro, 2009.

LUENGO, F. C. A vigilância punitiva: a postura dos educadores no processo de patologização e medicalização da infância [online]. São Paulo: Editora UNESP; São Paulo: Cultura Acadêmica, 2010.

MARQUES, V.R.B. A Medicalização da Raça: Médicos, Educadores e Discurso Eugênico. Campinas: Editora da UNICAMP, 1994.

MOYSÉS, M. A. A.; COLLARES, C. A. Inteligência abstraída, crianças silenciadas: as avaliações de inteligência. Psicologia USP, v.8, n.1, São Paulo, 1997, p. 63-89.

MOYSÉS, M. A. A.; COLlARES, C. A. Dislexia existe? Questionamentos a partir de estudos científicos. Cadernos Temáticos $\mathrm{n}^{\circ}$ 8. Dislexia: subsídios para políticas públicas/ Conselho Regional de Psicologia da $6^{\mathbf{a}}$ Região - São Paulo: CRPSP, 2010.

ORTEGA, F. et. a.l. A ritalina no Brasil: produções, discursos e práticas. Interface Comunic., Saúde, Educ., v.14, n. 34, p. 499-512, 2010.

PATTO, M. H. S. Para uma crítica da razão psicométrica. In: PATTO, M, H, S. Mutações do Cativeiro: escritos de psicologia e política. São Paulo: Hacker Editore/ Edusp, 2000, pp.65-83.

SAYÃO, R. Profusão de estímulos. Jornal Folha de São Paulo. Disponível em: <http://zip.net/bcsNjy>. Acesso em: 15 fev. 2014.

\section{Como referenciar este artigo}

COLOMBANI, Fabiola.; MARTINS, Raul Aragão. O movimento higienista como política pública: aspectos históricos e atuais da medicalização escolar no Brasil. Revista on line de Política e Gestão Educacional, Araraquara, v.21, n.1, p. 278-295, 2017. Disponível em: <http://dx.doi.org/10.22633/rpge.v21.n.1.2017.9788>. ISSN: 1519-9029.

Submetido em: 30/11/2016

Aprovado em: 30/03/2017 